\title{
Stable silylenes: Synthesis, structure, reactions
}

\author{
Robert West and Michael Denk* \\ Department of Chemistry, University of Wisconsin-Madison, 1101 University Avenue, \\ Madison, WI 53706
}

\begin{abstract}
Two dicoordinate silicon compounds have been prepared, the unsaturated silylene 4 and the saturated analog 5 . Compound $\mathbf{4}$ is surprisingly stable, unchanged after boiling in toluene at $150^{\circ} \mathrm{C}$ for four months. 5 decomposes slowly at $25^{\circ} \mathrm{C}$. Some chemical reactions of 4 are described, and the structures and bonding in both silylenes are considered. The additional stability of 4 over 5 is ascribed to aromatic stabilization in the 6 $\pi$-electron system of 4 .
\end{abstract}

Silylenes, $\mathrm{R}_{2} \mathrm{Si}$ : are the silicon counterparts to carbenes of organic chemistry. However, they play an even more important role in silicon chemistry than carbenes do in carbon chemistry. Silylenes are key intermediates in many thermal and photochemical reactions of organosilicon compounds. (1) Many silylenes have now been observed and identified when isolated in argon or hydrocarbon matrices at very low temperatures. However, most silylenes are extremely unstable, decomposing rapidly at temperatures above $77 \mathrm{~K}$.

The chemistry of divalent silicon compounds dates from 1986, when the remarkable $\pi$ complex, $\left(\mathrm{Me}_{5} \mathrm{C}_{5}\right)_{2} \mathrm{Si}$, was synthesized by Jutzi and co-workers. (2) A few other compounds of divalent silicon are known, for instance the phosphorus complex, $\left[\mathrm{Me}_{2} \mathrm{PC}\left(\mathrm{SiMe}_{3}\right) \mathrm{PMe}_{2}\right]_{2} \mathrm{Si}$.(3) These compounds however have coordination numbers greater than 2 and behave rather differently from silylenes in their chemical reactions.

Stable germylenes and stannylenes, the germanium and tin counterparts to silylenes, are well known. (4) In 1991 Arduengo and co-workers at the du Pont Co. published the synthesis of a stable carbene, the five-membered ring compound 1a. Subsequently a family of stable carbenes, 1b-f, has been reported.(5) The preparation of these surprising substances left silicon as the only element of group 14 with no dicoordinate, divalent compound stable at ordinary temperature.

These striking experiments by the du Pont group suggested that silicon compounds with structures similar to 1 might be good candidates for isolation at room temperature. There was, however, some contrary evidence; the germylene and stannylene, $\mathbf{2 a}$ and $\mathbf{2 b}$, are stable compounds but the corresponding silylene, $2 c$, was reported to decompose near $77 \mathrm{~K}$.(6)

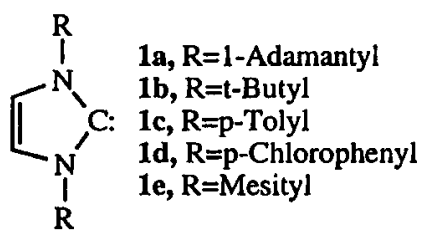<smiles>CC1=C(C)N(C)CN1C</smiles>

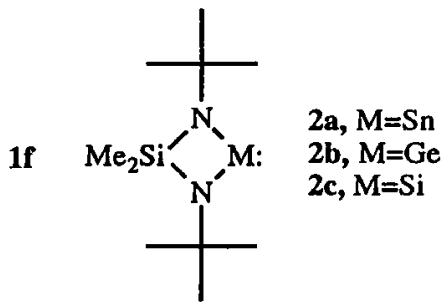

The first room temperature stable silylene was reported in 1994. (7) The synthesis proceeds according to Scheme 1, starting from t-butylamine and glyoxal. The final step, dehalogenation of the dichloride 3, required surprisingly vigorous conditions: Refluxing with molten potassium metal in THF for three days.

Scheme 1
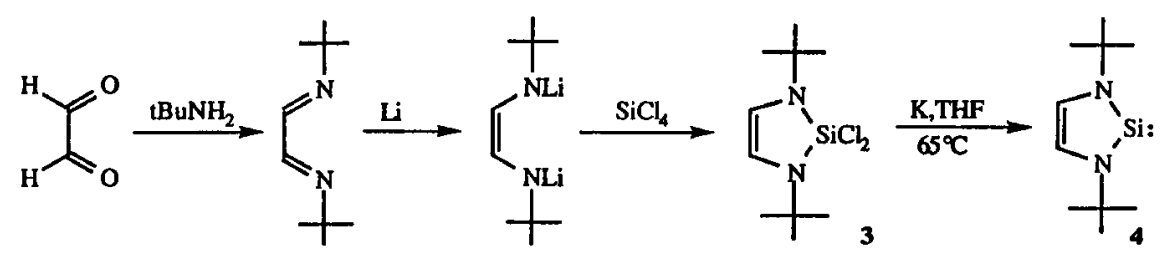

Silylene 4 is a colorless crystalline compound with truly surprising thermal stability. It can be distilled without decomposition at $90^{\circ} \mathrm{C}(0.1$ Torr $)$ and was unchanged after heating in toluene solution at $150^{\circ}$ for four months. In the solid state, decomposition of 4 takes place only at its melting point, $\sim 220^{\circ} \mathrm{C}$. 
Silylene 4 is also distinctly less reactive than transient silylenes. It does not insert into $\mathrm{Si}-\mathrm{H}$ bonds, nor does it react with diphenylacetylene or $\mathrm{Me}_{3} \mathrm{SiC} \equiv \mathrm{CSiMe}_{3}$, all of which are typical reactions for silylenes. Unlike typical silylenes, 4 has no Lewis acidic behavior; it does not form complexes even with rather strong Lewis bases such as pyridine, triethylamine, or THF. Reactions do take place between 4 and alcohols, water, or oxygen, to give products whose structures have not yet been determined. Other chemical reactions of 4 are described below.

Recently, a second example of a stable silylene has been synthesized: 5 , the saturated analog to 4.(8) Like 4, 5 is a colorless crystalline solid. The synthetic route leading to 5 is similar; but in order to obtain satisfactory yields, it proved necessary to use the dibromo compound rather than the dichloro derivative as a precursor. Compound $\mathbf{5}$ is distinctly more reactive and less stable than the unsaturated silylene 4 . In particular, 5 behaves as a Lewis acid toward strong Lewis bases such as pyridine, and slowly decomposes when stored as a solid at $25^{\circ} \mathrm{C} .(8,9)$

Silylenes 4 and 5 have been studied by X-ray crystallography. Crystals of 4 , however, were invariably disordered. X-ray diffraction showed that the molecules of $\mathbf{4}$ were monomeric, but accurate values for bond lengths and angles could not be determined. These structural parameters were eventually obtained by fitting the electron diffraction pattern of 4 ; the resulting structure is shown in Fig. 1a. For silylene 5 no such difficulties arose. The structure, determined by $\mathrm{X}$-ray crystallography, is shown in Fig. $1 \mathrm{~b}$.
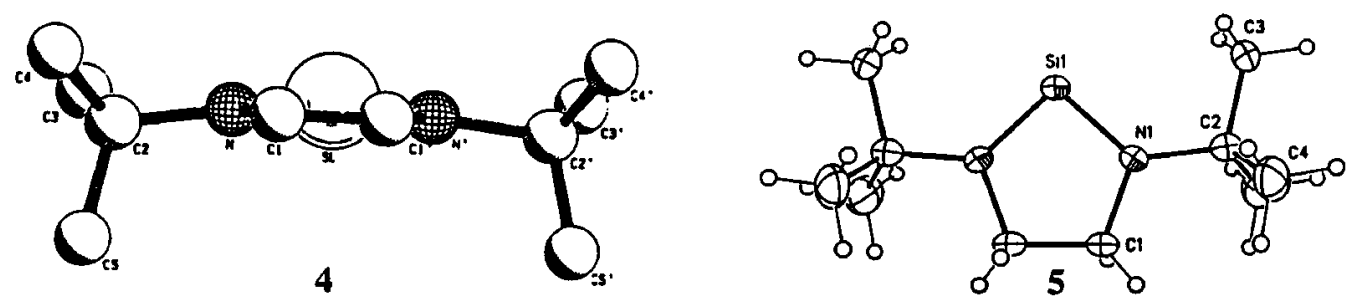

Fig. 1 Structures of Stable Silylenes.a. left, Structure of 4 from electron diffraction, reprinted with permission from ref. 7. b. right, Structure of 5 from X-ray Crystallography.

The five-membered ring in $\mathbf{4}$ is nearly planar but that in $\mathbf{5}$ is puckered, as shown in Fig. 1b. The N-Si-N bond angles are $90.5^{\circ}$ for 4 and $92.0^{\circ}$ for 5 . As expected, the intra-ring $\mathrm{N}-\mathrm{C}$ distance is distinctly shorter in $4(140 \mathrm{pm})$ than in $5(149 \mathrm{pm})$. The Si-N bond distances, $175 \mathrm{pm}$ for 4 and $172 \mathrm{pm}$ for 5 , are slightly longer than for single bonds from nitrogen to tetravalent silicon. However, bonds to divalent silicon are expected to be longer, by about $8 \mathrm{pm}$. The Si-N bond distances in 4 and 5 are therefore consistent with partial double bonding in these molecules.

The properties of silylenes $\mathbf{4}$ and 5 raise fascinating questions of chemical bonding. First, why are these molecules stable? And, why is $\mathbf{4}$ so much more inert than 5 ?

Steric hindrance may be a factor, but it seems unlikely that it is a major one. Inspection of models shows that the silicon atoms in the stable silylenes are not highly protected sterically. Electron-donation from nitrogen to silicon is likely to be important in stabilizing both $\mathbf{4}$ and $\mathbf{5}$, as shown in resonance drawings below. Greater $\pi$-donation, $N \rightarrow S i$, would be expected for 5<smiles>CCCCN1C=CN(C(C)(C)C)[Si]1CCCC</smiles><smiles></smiles><smiles>CN1[Si]N2CCC(C)(C)N1[Si]2</smiles>

6

than for $\mathbf{4}$, since the nitrogens in 5 should be the more basic, and indeed the Si-N bond length is shorter in 5 than in 4 , as mentioned above.

What then accounts for the much greater stability of 4 compared to 5 ? It has been suggested that 4 is stabilized by aromatic resonance, since it forms a $6 \pi$-electron cyclic system, 6. $(7,9)$ Possible evidence for aromatic delocalization in 4 could come from proton NMR data. The chemical shifts of the vinyl protons in the model compounds, 3 and the corresponding dihydride 7, lie at $5.73 \mathrm{ppm}$ for the dichloride 3 and at $6.00 \mathrm{ppm}$ for 7 . In 4 the vinyl proton resonance is shifted downfield to $6.75 \mathrm{ppm}$, consistent with deshielding due to an aromatic ring current.

To explore this possibility further, quantum chemical calculations were carried out for the isodesmic reactions of the model compounds 8 and 9 with dihydrogen to give the corresponding dihydrides (Scheme 2). These calculations showed that the reaction of 8 with $\mathrm{H}_{2}$ is about 11 
Scheme 2<smiles>CC1C=CN[SiH2]1</smiles><smiles>CC1CCNC1</smiles>

$\mathrm{kcal} / \mathrm{mol}$. less exothermic than that of 9 . This difference may reflect aromatic resonance energy in 8 , reducing the enthalpy of the hydrogenation reaction.

The HeI and HeII photoelectron spectra have also been obtained for 4 and 5,(16) and for the unsaturated dihydride 7 . In both 4 and 7 , the lowest energy ionization was attributed to an orbital of the $\pi$ system (C-C bonding, $\mathrm{C}-\mathrm{N}$ antibonding). In 7, this first ionization was observed at $6.56 \mathrm{eV}$, but for 4 it was significantly higher, $7.13 \mathrm{eV}$, corresponding to significant participation by the $\mathrm{Si}$ p orbital, stabilizing the ring $\pi$ orbital as expected for aromatic resonance. The ionization energies of the lone pair electrons in 4 and 5 were not very different, 8.21 and $8.11 \mathrm{eV}$, indicating that hydrogenation of the $\mathrm{C}=\mathrm{C}$ bond in $\mathbf{4}$ does not greatly change the nature of the lone pair.

All of these indications are consistent with some degree of aromatic delocalization in 4. Also, a recent theoretical paper supports the concept of aromatic delocalization in the cyclic $\mathrm{Si}-\mathrm{N}$ molecule, (HNSi) $3,(10)$ which also possesses 6 pi-electrons. However, the question is far from closed. A distinctly different model, also based on photoelectron studies, has been put forward by Arduengo et. al., in which the bonding is viewed in terms of $\sigma$-donation from a diimine to a neutral $\mathrm{Si}$ atom, (10), and both theoretical and experimental evidence has been interpreted as showing that aromatic delocalization is not a significant factor in the carbenes, 1.(11) Further theoretical and experimental studies are needed.

The ${ }^{29}$ Si NMR chemical shifts, $+78.3 \mathrm{ppm}$ for 4 and $+119 \mathrm{ppm}$ for 5 , are strongly deshielded as expected for silylene silicon atoms. Comparison can be made with the tetravalent compounds 3 and 7 , which show ${ }^{29} \mathrm{Si}$ chemical shifts of -40.7 and $-43.8 \mathrm{ppm}$.

The decreased reactivity of compound 4 compared with transient silylenes is mentioned above. Since 4 has little or no Lewis acidity, it does not react in the electrophilic manner typical for silylenes. Silylene $4 \mathrm{can}$, however, react as a Lewis base, i. e., as a nucleophilic reagent. The availability of the stable silylene has made possible several new types of reactions not known for transient silylenes.

In a number of ways the reactions of 4 resemble those of phosphines, $R_{3} P$ :. Examples are provided by the reactions of 4 with covalent azides. Phosphines are known to react with azides to give phosphineimines, $\mathrm{Ph}_{3} \mathrm{P}=\mathrm{NR}$. In similar fashion, 4 reacted with triphenylmethyl azide in THF to give the silanimine 11, as its THF complex.(12) This reaction provides a new method for synthesizing compounds containing a $\mathrm{Si}=\mathrm{N}$ double bond, which have previously been made by salt elimination reactions.(13)

Reactions of 4 with less hindered azides can be more complex. With trimethylsilyl azide, the isolated product was the azidosilane 12. The formation of 12 can be rationalized, however, as proceeding through the initial formation of a silanimine, followed by addition of $\mathrm{Me} 3 \mathrm{Si}_{3} \mathrm{~N}_{3}$ across the $\mathrm{Si}=\mathrm{N}$ double bond. When 4 was treated with 1-adamantyl azide, the product was the silatetrazoline 13. Once again this product may have resulted from initial formation of a silanimine, followed in this case by $2+3$ cycloaddition of the azide to the $\mathrm{Si}=\mathrm{N}$ double bond.

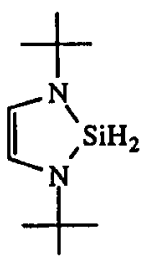

7

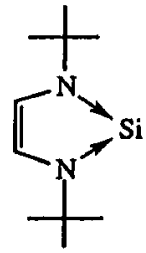

10

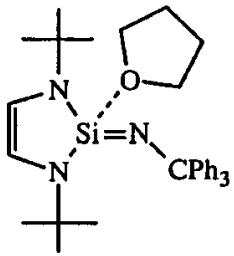

11

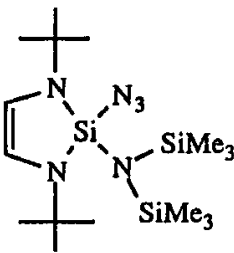

12

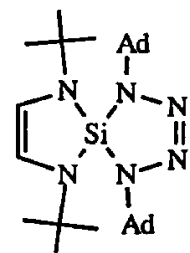

13

Silylene 4 also behaves somewhat like a phosphine in its interactions with metal carbonyls. $(14,15)$ Typical reactions involve substitution of silylene for $\mathrm{CO}$, to give a silylenemetal complex. Three examples are shown in Scheme 3. This complex with $\mathrm{Ni}(\mathrm{CO})_{4}$ is both the first silylene-nickel complex, and the first example of a bis-silylene metal complex free of stabilization by Lewis base donors.(14) Its structure is shown in Fig. 2. 

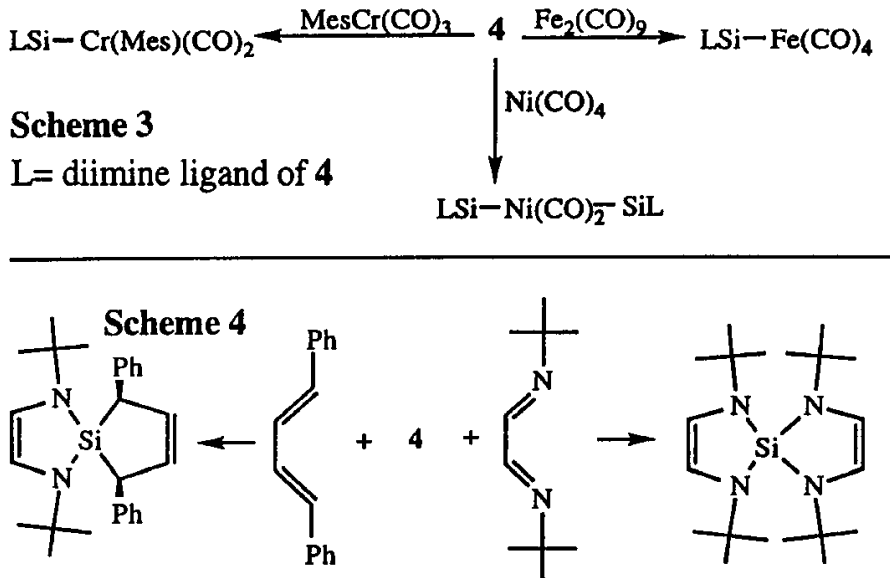

14

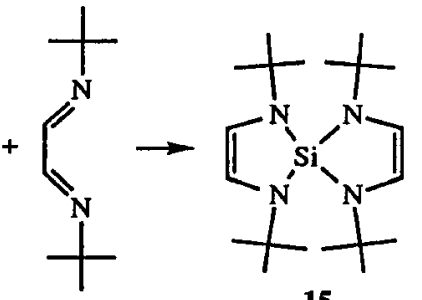

15

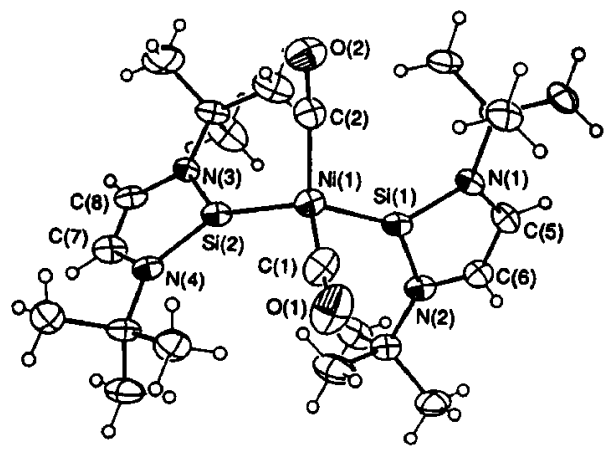

Fig. 2 Thermal ellipsoid diagram for silylene-nickel complex, (4) ${ }_{2} \mathrm{Ni}(\mathrm{CO})_{2}$. Reprinted with permission from ref. 14.

In all three complexes the Si-metal bond is short ( $\mathrm{Si}-\mathrm{Fe} 219, \mathrm{Si}-\mathrm{Ni} 221, \mathrm{Si}-\mathrm{Cr} 228 \mathrm{pm}$ ). These distances are about $10 \mathrm{pm}$ less than for typical Si-metal single bonds, consistent with partial back-bonding from the metal to the $p$ orbital on silicon. Reactions of 4 to form silylene-metal complexes appear to be general, and many more examples are likely to be prepared in the future.

Silylene 4 also reacts with some dienes to give $1+4$ cycloaddition products. With trans 1,4-diphenylbutadiene, disrotatory ring closure takes place to give the cis-product, 14 as expected for a singlet silylene (Scheme 4). A second example is the reaction of 4 with the diimine used in its synthesis. The product is the spiro compound 15.(15)

With the discovery of the stable dicoordinate silicon compounds, 4 and 5, silylene chemistry has entered a new and exciting phase. Additional examples of stable silylenes are very likely to be synthesized soon. New kinds of chemical reactions seem likely to result from studies of the reactivity of stable silylenes; experimental and theoretical investigations of stable silylenes may provide some new insights into chemical bonding of silicon.

\section{Acknowledgements}

Research on silylenes at Wisconsin has been supported by the National Science Foundation; support from the Alexander von Humboldt Stiftung is also gratefully acknowledged. The authors thank the many collaborators, at Wisconsin and elsewhere, who have contributed theoretical or experimental data on stable silylenes; names of these individuals appear in references.

\section{References}

1. P. Jutzi, D. Kanne, C. Krüger, Angew. Chem. Int. Ed. Engl., 25, 164 (1986).

2. For reviews on silylenes see P. P. Gaspar in M. Jones Jr., R. A. Moss, ed's, Reactive Intermediates, Wiley, New York. Vol. 1, 1978, p. 229-278; Vol. 2, 1981, pp. 335-385; Vol. 3, 1985, pp. 333-427; O. M. Nefedov, M. P. Egorov, A. I. Ioffe, C. G. Menchikov, P. S. Zuev, V. L. Minikin, B. Y. Simkin, M. N. Glukhovtsev, Pure Appl. Chem. 64, 265 (1992).

3. H. M. Karsch, U. Keller, S. Gamper, G. Muller, Angew. Chem. Int. Ed. Engl., 29, 295 (1990).

4. D. H. Harris, M. F. Lappert, J. Chem. Soc., Chem. Commun., 895 (1974).; M. S. J. Gyname, D. H. Harris, M. E. Lappert, P. P. Power, P. Riviere, M. Riviere-Baudef, J. Chem. Soc., Dalton Trans., 2004 (1977); D. H. Harris, M. F. Lappert, J. B. Pedley, G. J. Sharp, J. Chem. Soc., Dalton Trans., 945 (1976).

5. A. J. Arduengo III, H. V. Rasika Dias, R. L. Harlow, M. Kline, J. Am. Chem. Soc., 114, 5330 (1992).

6. M. Veith, E. Werle, R. Lisowski, R. Köppe, H. Schnöckel, Chem. Ber., 125, 1375 (1992).

7. M. Denk, R. Lennon, R. Hayashi, R. West, A. V. Belyakov, H. P. Verne, A. Haaland, M. Wagner, N. Metzler, J. Amer. Chem. Soc., 116, 2691 (1994).

8. M. Denk, R. K. Hayashi, R. West, submitted for publication.

9. M. Denk, J. C. Green, N. Metzler, M. Wagner, J. Chem. Soc., Dalton Trans., 2405 (1994).

10. L. Nyulászi, T. Kárpáti, T. Veszprémi, J. Am. Chem. Soc., 116, 7239 (1994).

11. a. A. J. Arduengo III, H. Bock, H. Chen, M. Denk, D. A. Dixon, J. C. Green, W. A. Herrmann, N. L. Jones, M. Wagner, R. West, J. Am. Chem. Soc., 116, 6641 (1994); b. A. J. Arduengo, D. A. Dixon, R. L. Harlow, K. K. Kumashiro, C. Lee, W. P. Power, K. Zilm, J. Am. Chem. Soc., 116, 6361 (1994);

c. A. J. Arduengo, H. V. Rasika Dias, D. A. Dixon, R. L. Harlow, W. T. Klooster,

T. F. Koetzle, J. Am. Chem. Soc., 116, 6812 (1994).

12. M. Denk, R. K. Hayashi, R. West, J. Am. Chem. Soc., 116, 10813 (1994).

13. For a review see, I. Hemme, U. Klingebiel, Advances in Organometallic Chemistry, 39, in press (1995).

14. M. Denk, R. K. Hayashi, R. West, J. Chem. Soc., Chem. Commun., 33 (1994).

15. M. Denk, R. West, unpublished studies. 